The following interesting abnormality has, however, been encountered. On six occasions between July 8 and August 1 we found that as the frequency was increased beyond the point where reflections from both layers were returned, the $F$ echo completely disappeared, leaving the $E$ echo still in evidence. The $E$ layer was not penetrated until a considerably higher frequency had been reached. (In two tests, indeed, the critical penetration frequency for this persistent $E$ layer was greater than 9.65 megahertz.) This is, of course, a complete reversal of ordinary experience. Usually $E$ echoes very soon cease to appear as the frequency is increased beyond the point of lower layer penetration.

A good example of this disappearance of $F$ echoes is shown in Fig. 1, wherein the regions from which the energy is returned are indicated by the conventional symbols. A close examination of the actual photographic records confirms our belief that the upper curve and the lower two curves represent signals returned from different regions.

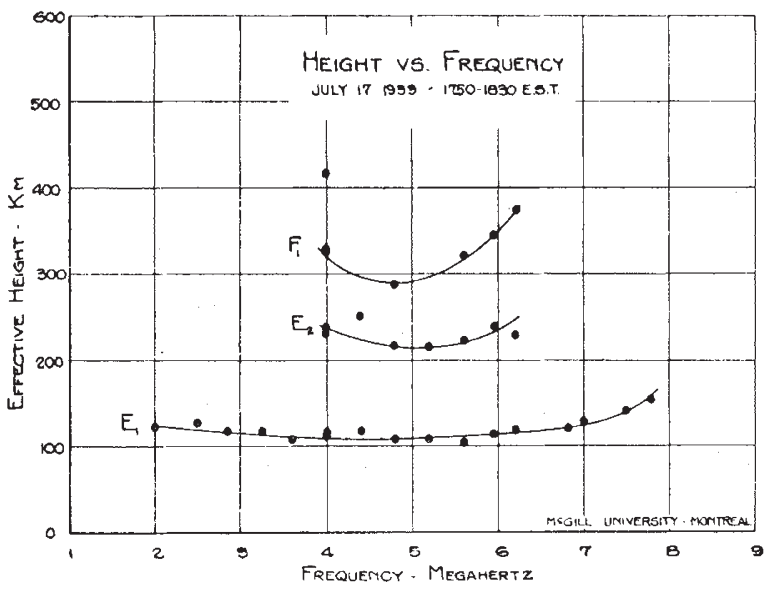

FIG. 1.

Occasionally echoes were received from the intermediate region, while at other times the two layers appeared to merge, giving a practically continuous distribution of heights, with no clearly defined line of demarcation. This phenomenon is also found in unpublished records obtained in Ontario during the week of the August 1932 eclipse.

In the present series of tests the method of Breit and Tuve has been employed, the transmitting and receiving stations being separated by $\mathbf{3} \cdot \mathbf{5} \mathrm{km}$. No means of checking polarisation was available. IJuring this season there have been decidedly more thunderstorms than is customary in the district, but so far no correspondence has been traced between unusual echo phenomena and storms in progress in the vicinity. We recognise, however, that, as pointed out by Appleton and Naismith ${ }^{1}$, it may be necessary to make a statistical analysis of storms in a much larger neighbourhood to establish a connexion. Magnetic data are now under examination for evidences of correlation.

${ }^{1}$ Proc. Phys. Soc., 45, 389, May 1, 1933.

\section{Blood Groups and Racial Relationships}

$\mathrm{P}$ ROF. R. RUGGLES GATES deseribed in a paper read on September 8 at Leicester before Section H (Anthropology) of the British Association the results of his recent work on the blood groups of the coastal Indians of British Columbia. Of 300 individuals tested, 14 per cent were $A$ and the remainder 0 with the exception of two individuals who were $B$, a result which seems to indicate that before intermixture with white blood occurred, these Indians, like those in other parts of North and South America, were originally all 0 . The present populations of north-eastern Asia now have a high percentage of $B$ as well as $A$, hence the emigration from Asia to America must have ceased before the populations in Asia from which the Indians were derived became impregnated with $A$ or $B$.

'Peripheral' peoples such as the Australian natives, the Maori, the Bushmen of South Africa and the Lapps of northern Europe have $A$, but no $B$ except in cases of racial crossing. Among 400,000 individuals tested in all parts of the world, the pan-human blood grouping is 37 per cent 0,38 per cent $A, 18$ per cent $B, 7$ per cent $A B, A$ thus being older and more widespread than $B$. Both have spread through the human race by repeated mutations as well as by crossing and migration of races. Since the American Indians may be regarded as more advanced than the Australian aborigines and the Bushmen, who have $A$, and since they are believed to have entered North America in relatively recent times, there appears to be some difficulty in explaining the absence of both $A$ and $B$ from pure-blooded Amerindians.

Prof. Ruggles Gates offered the following as a possible solution. A fringe of islands and archipelagoes stretches down the eastern Asiatic coast from Sakhalin through Japan, Formosa and the Philippines to Borneo. Hrdlička has pointed out that some of the native tribes in these islands closely resemble the American Indians. The islands have afforded a considerable degree of isolation from the continent : people such as the Gilyaks of Sakhalin and the Tso of Formosa have relatively low percentages of $A$ and $B$. They possibly represent remnants of a race originally 0 , from which the Amerindians were derived, and have since been altered in varying degrees by infiltration from the continent of Asia of peoples having $A$ and $B$.

\section{University and Educational Intelligence}

A course of twenty-four University Extension lectures on "Man and the Physical World" will be given by Dr. A. C. R. Wakeman at Gresham College, Basinghall Street, E.C.2, on Wednesdays at 7.30 commencing on October 4. The course will be divided into two parts, namely, "History of the Advance of Physical Science" (October 4-December 20) and "Common Physical Phenomena in their Relation to Man" (January 10-April 11). Further particulars of this and other courses can be obtajned from the University Extension Registrar, University of London, South Kensington, London, S.W.7.

Education in India in 1930-31 is briefly reviewed by the Educational Commissioner with the Government of India in a pamphlet recently issued from 